\title{
Treatment of Primary Breast Cancer at the Surgical Unit of the Charité 1984-1998
}

\author{
Klaus-Jürgen Winzer ${ }^{\mathrm{a}}$ Anika Buchholz ${ }^{\mathrm{e}}$ Hans Guski ${ }^{\mathrm{b}}$ Hans-Dieter Frohberg ${ }^{\mathrm{c}}$ \\ Felix Diekmann $^{c}$ Kurt Possinger ${ }^{\mathrm{d}}$ Willi Sauerbrei $^{\mathrm{e}}$ \\ aBrustzentrum Charité, \\ bInstitut für Pathologie, \\ 'Institut für Radiologie, \\ ${ }^{\mathrm{d}}$ Medizinische Klinik und Poliklinik, Universitätsmedizin Berlin,

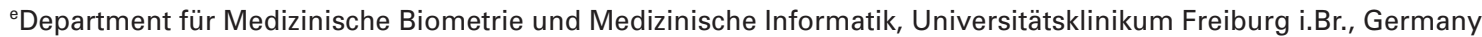

Keywords

Clinical cancer register

\section{Summary}

Background: We have analyzed the patient population of one clinic (Charité) over a period of 15 years. Besides the changes in the technical facilities and therapeutical guidelines during these years, this period also reflects the changes in the health system attributable to the reunification of East and West Germany. Until now only few analyses for breast cancer patients from the German speaking area have been reported. Patients and Methods: All 2,062 patients undergoing surgical treatment for breast cancer between 1984 and 1998 were documented and followed up until 2007. The analysis included 1,560 patients with a primary breast cancer who fulfilled certain inclusion criteria. The treatment strategies applied to this population are presented in 3 time periods (19841990, 1991-1993, and 1994-1998). The effects of prognostic factors on overall survival were investigated using univariate analyses. Results: The percentage of pT1 tumors changed from $50.7 \%$ in the first period to $63.1 \%$ in the third period. The percentage of node-negative patients hardly changed with time (on average $61.6 \%$ ). However, the percentage of patients with less than 10 assessed nodes decreased from $48.4 \%$ to $6.7 \%$ and $2.5 \%$ for the 3 periods, respectively. Therapeutic strategies changed drastically. Survival rate increased substantially, most likely due to improved therapeutic strategies, but also for other reasons not considered in the analysis.

\section{Schlüsselwörter \\ Krebsregister}

\section{Zusammenfassung}

Hintergrund: Es wird beispielhaft die Patientenpopulation einer Klinik (Charité) über einen längeren Zeitraum dargestellt. Dabei wechselten nicht nur die technischen Möglichkeiten und Therapierichtlinien sondern hier speziell auch das Gesundheitssystem nach der Wiedervereinigung Deutschlands für den Einzugsbereich der Klinik. Insgesamt finden sich nur wenige Analysen von Kliniken im deutschsprachigen Raum zum Brustkrebs. Patienten und Methoden: Von 1984 bis 1998 wurden (mit einer Nachbeobachtungszeit bis 2007) alle Patientinnen mit einer operativen Therapie eines primären Mammakarzinoms erfasst. Von diesen 2062 Patientinnen gingen durch festgelegte Ausschlusskriterien 1560 Patienten mit primärem Mammakarzinom in die Studie ein. Therapiestrategien dieser Patientengruppe werden über 3 Zeitperioden (1984-1990, 1991-1993 und 1994-1998) dargestellt. In univariaten Analysen werden die Effekte prognostischer Faktoren für die Gesamtüberlebenszeit untersucht. Ergebnisse: Der Prozentsatz der pT1-Tumoren stieg von 50,7 in der ersten Periode auf 63,1 in der dritten Periode. Die Lymphknotennegativität (durchschnittlich 61,6\%) variiert kaum, jedoch fiel der Prozentsatz von Patientinnen mit weniger als 10 untersuchten Lymphknoten von 48,4 über 6,7 auf 2,5. Beim therapeutischen Vorgehen gab es im untersuchten Zeitraum beträchtliche Änderungen. Vermutlich wegen geeigneterer Therapiestrategien und wegen weiteren Änderungen aus anderen, in der Analyse nicht erfassten Gründen nahm die Überlebenswahrscheinlichkeit deutlich zu.

\section{KARGER \\ Fax +497614520714 \\ Information@Karger.com} www.karger.com

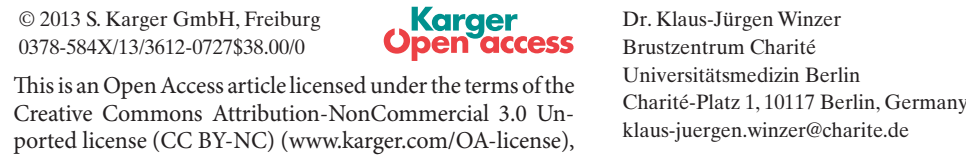

This is an Open Access article licensed under the terms of the Creative Commons Attribution-NonCommercial 3.0 Unported license (CC BY-NC) (www.karger.com/OA-license) applicable to the online version of the article only. Distribution permitted for non-commercial purposes only. 


\section{Introduction}

In the 1970s important trials were initiated aimed at improving treatment for patients with primary breast cancer. As the results of individual trials investigating similar questions sometimes yielded different or even conflicting findings, it became obvious that, to determine the value of specific components of the treatment strategy, systematic reviews and meta-analyses were required. The establishment of the Early Breast Cancer Trialists Collaborative Group (EBCTCG) [1] in the early 1980s was a milestone in improving and harmonizing the treatment of patients with breast cancer worldwide. The results of the meta-analyses of the EBCTCG [2] had a drastic influence on changes in surgical procedures from mastectomy to breast-conserving treatment (BCT) followed by radiotherapy (RT). The role of adjuvant therapy was discussed controversially: Is it preferable to use chemotherapy and/or hormonal therapy? Other factors that also played a role in determining a suitable treatment strategy, e.g. menopausal status, tumor size and number of positive lymph nodes, were also investigated. Based on the results of clinical trials, treatment strategies changed radically in the 80 s and 90 s. For centers in the former German Democratic Republic (GDR), the political changes in the late 80 s also had a far-reaching influence on the clinical situation. Here we illustrate these treatment changes for the Charité, which was the leading clinic in the GDR. For the German speaking region, there were very few reports on prognostic factors based on a non-selected patient population with a long-term follow-up over this period. Publications include clinical analyses from the First Women's Hospital of the Ludwig-Maximilian's University (Munich) and the gynecological clinic of 1,656 consecutive female patients over the years 1981-1990 [3], and from the Horst Schmidt Clinics (HSK; Wiesbaden) for the years 1981-1990 [4], and the retrospective clinical cohort study BRENDA, which includes 3,658 early-stage breast cancer patients [5].

We present data originating from this period of significant changes in treatment strategies for a nearly unselected population of patients with primary breast cancer. We applied detailed exclusion criteria to exclude any 'unusual' cases (see below) and assigned cases to subgroups defined by time periods and standard prognostic factors. We also present longterm results of overall survival. Due to the importance in the effect of prognostic factors, for this analysis we decided to exclude patients of over 80 years of age, although this exclusion is debatable.

This study was inspired by the careful documentation by the first author of all aspects of the treatment, standard prognostic factors and long-term follow-up for overall survival for primary breast cancer patients undergoing surgery during this period. We also depict the clinical situation at the Charite, including the political situation, diagnostics and treatment of patients as well as details about the available database. To illustrate the changes taking place between 1984 and 1998, we describe the prognostic factors for the patient population, the treatment strategies and the overall survival. The distribution of treatment strategies comprising surgery, RT and systemic therapy changed substantially over these 15 years. Using univariate analyses of overall survival time, we show that the consideration of standard prognostic factors agrees with current knowledge, and that overall survival rates improved during the period under investigation.

\section{Clinical Situation at the Charité}

The Charite (at the historic location in the GDR that corresponds to the 'Campus Mitte' today) provided an interdisciplinary tumor clinic (established and led by Prof. Fritz Gietzelt until 1959) with in-patient wards for radiation oncology, chemotherapy, surgery, gynecology and nuclear medicine. There were corresponding wards in the out-patient department, which provided an all-day service, and wards for diagnostic radiology, pathology und cytology as well as an experimental ward for radiobiology, which also conducted receptor assays. At that time, breast carcinoma surgery was conducted by surgeons; the surgery ward had been (spatially) affiliated to the surgical clinic in 1982 with the construction of the new surgically oriented center (COZ, which corresponds to the main hospital in-patient building today). Breast specimens were tested at the Charité's pathological institute, even though the pathological and cytological wards had existed for a longer time. The gynecological ward at the Charités tumor clinic did not conduct surgery for breast carcinomas, although surgery was performed at the university gynecological clinic (before the $\mathrm{COZ}$, with its own pathological unit, was built). However, the number of cases was small, around 30 and 50 cases per year. The number of surgical procedures conducted by gynecologists increased after the reunification of the 2 German states due in part to the support from the pharmacological industry (for a clinical trial center at the gynecology department, similar to those in several centers in the western part of the country) and because in 1994 the main surgeon was sent to other clinics for 6 months. However, for various reasons, a number of well-trained doctors also left the department of surgery.

At the end of 1993, the first author assumed responsibility for the department of breast surgery. In this function, he also became the surgical consultant for the 'complex ward rounds' (ambulatory patient care) that took place 2 or 3 times a week together with a consultant for breast tumors. These interdisciplinary rounds have relevance for this discussion. There were 2 specific breast consultation departments that had identical tasks, but 1 was conducted by a consultant surgeon and the other by a consultant for radiation oncology. Symptomatic patients presenting risk factors in their anamnesis visited these specialist healthcare consultation hours and underwent mammography on the same day. If a suspicious or borderline result emerged, the patient waited for, or returned on the day of, a complex ward round. The consultants in this round (radiodiagnostician, surgeon, radiotherapist and chemotherapist) then decided on a course of possible surgery or additional examinations, which, ideally, were conducted on the same day so that a decision could be reached as quickly as possible. The similar procedure applied postoperatively or in a palliative situation concerning RT or systemic therapy. Patients were then individually given detailed information by the consultant doctors in the consultation hours. Although the day of examinations was very concentrated for the patients, this procedure meant that an interdisciplinary decision could be made on the same day, with the patients having the same contact person. After the political turnaround in 1990, this form of treatment could no longer be maintained due to health insurance formalities (the responsibility of individuals). However, interdisciplinary concurrence on a case then followed through the developing interdisciplinary tumor 
conferences. With this procedure, an interdisciplinary approach was ensured. More than $80 \%$ of all surgeries were conducted or guided by the same surgeon (first author) throughout the whole duration of the study.

\section{Diagnostics and Treatment for Patients with Primary Breast Cancer}

Up-to-date diagnostic methods were available so that practically every patient received mammography preoperatively and subsequently sonography. Initially, a TuR DG 40 (VEB Transformatoren- und Röntgenwerk 'Herrmann Matern', Dresden, Germany) mammography device was used, which showed a similar configuration to then existing device from Philips The film used was XR-10 without foil from ORWO (Original Wolfen), which was high-grained. However, this combination caused a radiation burden 10 times higher than the current standard. From August 1992 onwards, a Mammomat 2 (Siemens, construction year 1991) with a film with an intensifying screen MinR (Kodak) was used and, from 1996, a magnetic resonance tomography device (Magnetom Vision 1.5 T, Siemens) with the appropriate mamma coils. Initially, a Charité-internal malignancy coding system was used for mammography findings, although subsequently the BIRADS classification that uses percentages of parenchyma in a welldefined region was developed. However, the same observer assessed and graded breast density over the study period [6].

During the initial periods, hormone receptors were routinely determined according to the dextran-coated charcoal assay $[7,8]$ and later immunohistochemically [9]. Surgical and RT procedures changed over the decades. Breast-conserving operations were conducted routinely from 1986 onwards, although only for patients up to an age of 60 years (as radiotherapists feared fat necrosis) and for tumors of $\leq 20 \mathrm{~mm}$ [10]. This indication was enlarged over time. The surgical technique was based on Bernhard Fisher's theoretical approaches and on his clinical findings [11] Generally, the decision for a specific surgical method was made during the surgery after the results of a histological section were known.

Initially, all patients were treated with mastectomy and adjuvant radiation to the chest wall and the regional lymph nodes with $\mathrm{X}$-ray therapy $(250 \mathrm{kV})$ with a cumulative dose of $50 \mathrm{~Gy}$. In the 80 s and early 90 s, postmastectomy RT was delivered to the chest wall and, if indicated, to the regional nodes with ${ }^{60} \mathrm{Co}$, up to a total dose of $50 \mathrm{~Gy}$. In 1986, as mentioned above, restricted breast-conserving surgery was introduced. The breast including the chest wall, the internal mammary nodes and the lower axilla were treated with ${ }^{60} \mathrm{CO}$-wedge filter-rotation therapy, 2 Gy per fraction, 5 times weekly, up to a reference dose of $40 \mathrm{~Gy}$. The tumor bed was boosted with $2 \mathrm{~Gy}$ per fraction (reference dose $10 \mathrm{~Gy}$ ). From the mid-90s, the treatment volumes and total dose were adapted to the size and location of the tumor and the lymph node status according to guidelines, although these changed over time. In the 90 s, treatment with a betatron and a linear accelerator were also implemented.

Systemic therapy with CMF (cyclophosphamide, methotrexate, and fluorouracil) was initially introduced for tumors accompanied by positive lymph nodes or classified as pT3-4. Depending on the patient's body weight, 20-30 mg Tamoxifen (originally introduced 1976 as Novaldex ${ }^{\circledR}$ and available in the GDR under the brand name Zitazonium ${ }^{\circledR}$ ) was prescribed for 2 to 3 years. Subsequently, this was varied based on results from meta-analyses of the EBCTCG $[1,2]$.

During the initial period analyzed here, scientific exchange was conducted at national congresses, sometimes also with international participation. Clinic directors and other selected personnel, as members of socalled 'Reisekader' (authorized travel cadres), were able to participate in international conferences almost without restriction. In addition, there were well-equipped clinic libraries (especially the library of the tumor clinic). When BCT was introduced, the first author used the methods described in issue 5 of the World Journal of Surgery of October 1985 [11,12]. For systemic therapy, the first really established guideline was not published until 1988. This and the following guidelines were considered in

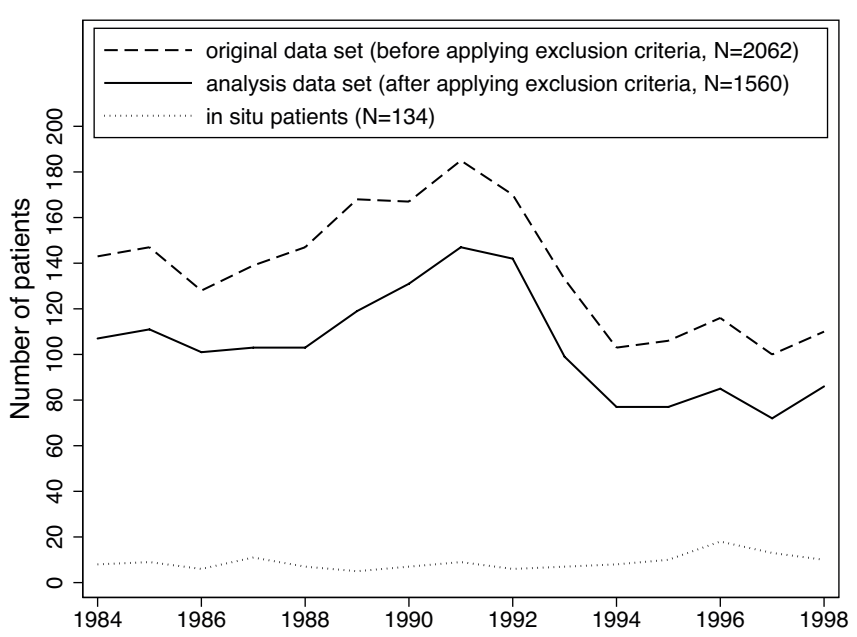

Fig. 1. Number of patients treated per year.

therapy planning from then on. The old procedures were modified if necessary.

From the end of 1989, participation in international congresses became more possible for everybody. Treatments necessary for systemic therapy were useable without any restrictions. Therefore, the internationally recognized prolongation of life through advances in systemic therapy should also be observable in our rates of overall survival. While in the early years only patients with positive lymph nodes received adjuvant systemic treatment, the therapeutic concept was later extended to more indications according to international standards.

The quality of our histopathological assessment increased over this time (as it did internationally), so that, in conjunction with more exact lymph node preparations, a higher quality of grading and also marking of resection margins with Indian ink could be realized. All in all, the medical standards for breast carcinoma treatment in university institutions were probably similar in both German States [13].

\section{Patients at the Charité}

\section{Database (K.J.W.)}

The first author had originally included all patients with breast cancer undergoing surgery at the unit from 1 January 1984 to 31 December 1998. These patients are shown in figure 1. However, for the analysis we defined some exclusion criteria (such as patients with metastasis or carcinoma in situ, see next section) to obtain a more homogeneous population, allowing a sensible calculation of survival rates and other statistics. This means that any patient not operated at the surgical clinic of the Charité or who had a primary tumor before 1 January 1984, although originally included in the database, was not taken into account for this study according to the exclusion criteria. Careful consideration of the exclusion criteria also allows an investigation of the influence of standard prognostic factors on overall survival. This will be the subject of a following paper. Some of the patients were treated within clinical trials in which not all treatment arms corresponded to the standard treatment at that time.

The Charité was basically open for treatment of any patient, although patients mainly came from Berlin and the surrounding area. After the political turnaround, a segregation of patients from western and eastern Germany occurred as they belonged to the different national health insurances systems; in East Berlin, the insurance premium level was initially at level of that in eastern Germany, but later became adjusted to the western standard, in contrast to the rest of the other member states of the former GDR. Health insurances made it more difficult for people from these 
former GDR states to come to the Charité, which led to a fall in the number of patients.

Since January 1984, at the Charité, the estrogen receptor content had been determined biochemically using the dextran-coated charcoal assay Carcinomas that absorb more than $10 \mathrm{fmol} / \mathrm{mg}$ cytosol protein of the steroid hormone were regarded as receptor positive [14]. Subsequently, an immunohistochemical method was introduced internationally and was soon established as the standard $[9,15]$. Although the cytochemical test was still often run in parallel (receptor analysis), for different evaluations the more probable variant was chosen according to the quality of the method at the time. In practice, since the cytochemical method [16] was not identical with the immunohistochemical method, for which a score or a percentage was given, the decision was always made against the cytochemical method if there were 2 different values.

In 1988/1989, typing and grading, including the mitosis rate, were assessed according to the standards still valid today using formalin-fixed paraffin-embedded tissue (FFPE) by the first author (K.J.W.) together with the head of breast cancer pathology department (H.G.). Missing data have been subsequently added, partially using data from research projects on a small scale (number of mitoses, grading, receptors, etc.). However, existing values have not been replaced even if they differed from those of the research projects.

\section{Exclusion Criteria}

In the original database 2,062 patients were included. Patients were excluded for the following reasons: metastasis $(n=63)$, previous carcinoma other than breast cancer $(n=73)$, primary breast cancer prior to this study $(\mathrm{n}=86)$, and breast cancer in situ $(\mathrm{n}=134)$.

As the investigation of standard prognostic factors was a second aim, we also excluded the small groups of patients with pt $0(\mathrm{n}=8)$ and patients older than 80 years $(n=123)$. The latter group has a very high risk of dying from other causes not related to breast cancer. The decision to use the age of 80 as the cut-off point was arbitrary. We also excluded a small group of patients $(\mathrm{n}=20)$ who had neo-adjuvant chemotherapy. Nowadays, this is a standard treatment, but it was still experimental during the inclusion period of patients in our study. Excluding these patients resulted in a more homogeneous population with respect to treatment strategies in our study. We also excluded 71 patients who died within the first month after surgery. For the database, survival time was measured in complete months; therefore, patients dying within the first month had survival time 0 . Death within 1 month is very unusual for a patient with primary breast cancer, and these very early deaths were often caused by other factors, e.g. some overlap with metastatic patients. Finally, we excluded 2 patients for whom most of the standard prognostic factors were missing. Altogether 502 patients were excluded (for some patients, several of the above-mentioned criteria applied simultaneously). Hence, the analysis data set contained 1,560 patients.

\section{Time Periods}

The political changes after the fall of the Berlin Wall (9 November 1989) and the political reunification of the 2 states (3 October 1990) had hardly any consequences on the treatment strategies, but there were constant adaptations to the new economic situation. We set the end of the first period (1 January 1984-31 December 1990) to the end of the GDR social care program for persons who were then insured within the health insurance system of the Federal Republic of Germany. From 1 January 1991, the German health insurance law was also extended to the 'new' German states (at first, for 1991, through a transitional office for social care). Because of this, we evaluated the period 1 January 1991-31 December 1993 as a transitory stage. At the beginning of the 90s, the personnel of the Charité's, similar to all academic establishments in the former GDR, had to undergo a personal and professional review by specialist groups of the so-called structural and appointment commission. New job appointments then followed towards the end of 1993 until the beginning of 1994.
This is why we chose 1 January1994 as the beginning of the third time period. Inclusion of patients ended at 16 December 1998.

\section{Follow-up and Statistical Methods}

Data in the original database were constantly updated with respect to death, newly appearing metastases or locoregional recurrence. If no such event occurred, the date of the last follow-up has been inserted. As the first author was responsible for the legally required transmission of cancer data for the whole clinic, until 1991, the death of a patient was usually known independently of loss to follow-up, and contributed to the statistic. The death of a patient reported by phone was also documented and used for these analyses.

At the starting time of the study, all data were noted on file cards and transferred to a punch card system and subsequently captures and calculations were conducted on a PC based on DOS. These data were, therefore, transferred first to a PC using the software NCSS5.03 (statistics and graphics), and were then converted to SPSS for Windows through a paradox database, as the NCSS database could not be directly transferred to SPSS. This approach was necessary because of the long-term follow-up.

Further information concerning date of death for some of the patients has been gained from contact with the cancer registries. For more details and some of the difficulties related to the use of this follow-up information see [17]. To avoid some potential biases caused by incomplete followup information of a larger number of the patients, we decided to use only the information available from the clinic. Of the 1,560 patients contained in our analysis, 221 have died.

All analyses are descriptive and results are mainly presented as percentages, means and other simple statistics. To illustrate trends over time between 1984 and 1998 we have used 3 approaches to present the statistics. These are sometimes shown in years; in some plots trends are better visible by smoothing the yearly figures (lowess running-line least-squares smoother with bandwidth 0.5 ) and we often consider the 3 periods as defined in the previous section. Concerning prognostic factors and treatment strategies, in our study the different groups were defined according to general criteria used in breast cancer (e.g. TNM) and the distribution of variables. Survival time was calculated as the time from the date of primary surgery to the date of death or the date of last information available at the clinic. Patients without a known date of death were handled as censored survival data.

Survival rates and corresponding $95 \%$ confidence intervals were estimated using the method of Kaplan-Meier [18]. They are given for the overall population and several subgroups defined by categories of standard prognostic factors, treatment strategies and time periods. As estimation of the effects of the various factors considered requires complex multivariable model building, we intended to present results of these analyses in a follow-up paper.

\section{Results}

\section{Patient Population}

Figure 1 shows the number of patients for each year from 1984 to 1998 . Overall, there were 2,062 patients in the database, of whom 1,590 met our inclusion and exclusion criteria. Of the 502 patients excluded, 134 were diagnosed with carcinoma in situ. After 1988, there is a strong increase in the number of patients and after 1991 a drop. This drop resulted from the de facto dissolution of the polyclinic structures of the cancer clinic, as well as the absence of the first author from the clinic for over 6 months without an adequate replacement. 
Table 1. Distribution of prognostic factors in 3 time periods. Number of cases and percentages (relative to all non-missing values)

\begin{tabular}{|c|c|c|c|c|}
\hline Factor & 1984-1990 & 1991-1993 & 1994-1998 & Overall \\
\hline Patients, $\mathrm{n}$ & 775 & 388 & 397 & 1,560 \\
\hline \multicolumn{5}{|l|}{ Age, years (\%) } \\
\hline$\leq 40$ & $61(7.9)$ & $20(5.2)$ & $25(6.3)$ & $106(6.8)$ \\
\hline $41-50$ & $184(23.7)$ & $69(17.8)$ & $72(18.1)$ & $325(20.8)$ \\
\hline $51-60$ & $196(25.3)$ & $130(33.5)$ & $137(34.5)$ & $463(29.7)$ \\
\hline $61-70$ & $172(22.2)$ & $108(27.8)$ & $108(27.2)$ & $388(24.9)$ \\
\hline$>70$ & $162(20.9)$ & $61(15.7)$ & $55(13.9)$ & $278(17.8)$ \\
\hline \multicolumn{5}{|c|}{ Meno. status, n (\%) } \\
\hline Premeno & $231(31.0)$ & $95(26.1)$ & $112(28.2)$ & 438 (29.1) \\
\hline Postmeno & $514(69.0)$ & $269(73.9)$ & $285(71.8)$ & $1,068(70.9)$ \\
\hline Missing & 30 & 24 & 0 & 54 \\
\hline \multicolumn{5}{|c|}{ Tumor size, n (\%) } \\
\hline$\leq 20 \mathrm{~mm}$ & $353(50.7)$ & $207(55.5)$ & $250(63.1)$ & $810(55.3)$ \\
\hline $21-50 \mathrm{~mm}$ & $305(43.8)$ & $154(41.3)$ & $133(33.6)$ & $592(40.4)$ \\
\hline$>50 \mathrm{~mm}$ & $39(5.6)$ & $12(3.2)$ & $13(3.3)$ & $64(4.4)$ \\
\hline Missing & 78 & 15 & 1 & 94 \\
\hline $15-25 \mathrm{~mm}^{\mathrm{a}}$ & $335(48.1)$ & $169(45.3)$ & $158(39.9)$ & $662(45.2)$ \\
\hline 0 & $449(62.3)$ & $217(57.6)$ & $253(64.2)$ & $919(61.6)$ \\
\hline $1-3$ & $159(22.1)$ & $80(21.2)$ & $78(19.8)$ & $317(21.3)$ \\
\hline $4-10$ & $93(12.9)$ & $39(10.3)$ & $36(9.1)$ & $168(11.3)$ \\
\hline$>10$ & $20(2.8)$ & $41(10.9)$ & $27(6.9)$ & $88(5.9)$ \\
\hline Missing & 54 & 11 & 3 & 68 \\
\hline \multicolumn{5}{|c|}{ Nodes assessed, n (\%) } \\
\hline $1-5$ & $126(20.0)$ & $5(1.3)$ & $4(1.0)$ & $135(9.7)$ \\
\hline $6-9$ & $179(28.4)$ & $20(5.4)$ & $6(1.5)$ & $205(14.7)$ \\
\hline $10-20$ & $288(45.6)$ & $234(62.9)$ & $213(54.2)$ & $735(52.7)$ \\
\hline$>20$ & $38(6.0)$ & $113(30.4)$ & $170(43.3)$ & $321(23.0)$ \\
\hline Missing & 144 & 16 & 4 & 164 \\
\hline \multicolumn{5}{|l|}{ Grade,n (\%) } \\
\hline G1 & $76(12.0)$ & $89(27.3)$ & $126(32.7)$ & $291(21.7)$ \\
\hline $\mathrm{G} 2$ & $265(41.7)$ & $155(48.3)$ & $190(49.2)$ & $610(45.4)$ \\
\hline G3 & $295(46.4)$ & $77(24.0)$ & $70(18.1)$ & $442(32.9)$ \\
\hline Missing & 139 & 67 & 11 & 217 \\
\hline
\end{tabular}

${ }^{a}$ Group of medium-sized tumors.

Meno = menopausal.
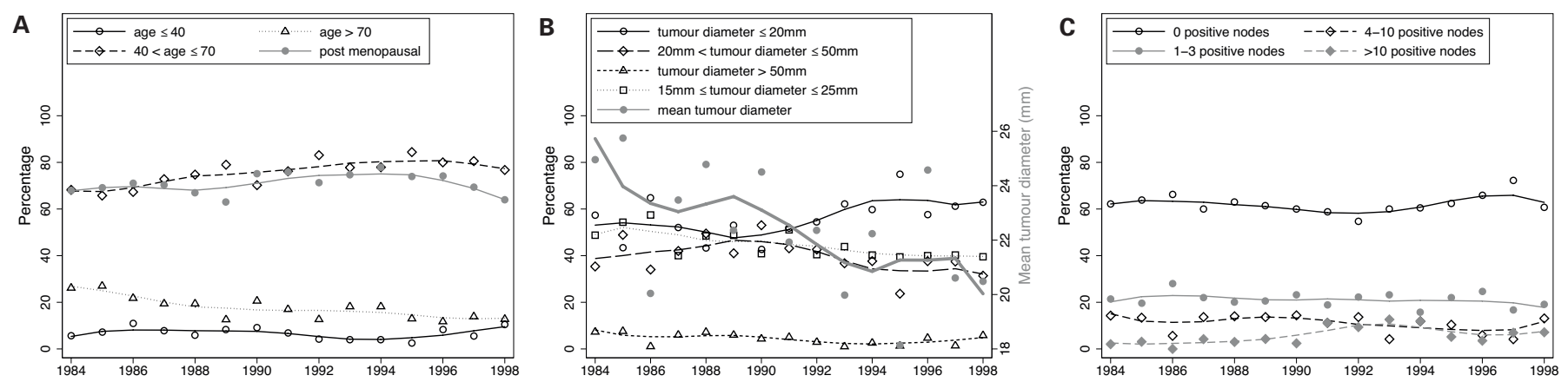

Fig. 2. A Age and menopausal status: Percentages per year and smoothed over several years. B Tumor size: Percentages per year and smoothed over several years. C Number of positive nodes: Percentages per year and smoothed over several years.

After this time, with only occasional exceptions, the first author was also the only surgeon present.

In table 1 and figure 2 we illustrate the distribution of the standard prognostic factors. Table 1 shows the results for the 3 time periods, whereas the figures show results per year. Prognostic factors are sometimes summarized in broader categories (e.g. ages 40-70 years). To illustrate time trends more effectively, we have also smoothed the yearly data.

No important changes in the age distribution occurred over the years. About $70 \%$ of the patients were postmenopausal.
The percentage of patients with a tumor size $\leq 20 \mathrm{~mm}$ hardly changed up to 1989 , but increased substantially in the following years. In the first period, about $51 \%$ had such a small tumor, compared to $63 \%$ in the third period. The mean tumor diameter decreased from about 25 to about $20 \mathrm{~mm}$.

The proportion of patients with more than 10 positive lymph nodes was very low in the first period $(2.8 \%)$ but more than doubled in the following periods, while the relative number of patients in the other groups $(0,1-3$ and $4-10$ positive lymph nodes) remains relatively constant. Approximately 
Table 2. Local and adjuvant therapy in the 3 time periods (percentages relative to all non-missing values)

\begin{tabular}{|c|c|c|c|c|}
\hline & 1984-1990 & 1991-1993 & 1994-1998 & Overall \\
\hline Patients, $\mathrm{n}$ & 775 & 388 & 397 & 1,560 \\
\hline \multicolumn{5}{|l|}{ Local therapy, n (\%) } \\
\hline BCT, no RT & $11(1.4)$ & $63(16.6)$ & $53(13.4)$ & $127(8.2)$ \\
\hline $\mathrm{BCT}+\mathrm{RT}$ & $74(9.7)$ & $136(35.8)$ & $189(47.6)$ & $399(25.9)$ \\
\hline Mastect., no RT & $389(50.9)$ & $157(41.3)$ & $105(26.5)$ & $651(42.2)$ \\
\hline Mastect., RT & $291(38.0)$ & $24(6.3)$ & $50(12.6)$ & $365(23.7)$ \\
\hline Missing & 10 & 8 & 0 & 18 \\
\hline \multicolumn{5}{|l|}{ Adjuv. therapy, n (\%) } \\
\hline Chemo + hormone & $11(1.4)$ & $13(3.4)$ & $26(6.6)$ & $50(3.2)$ \\
\hline Chemo only & $61(8.0)$ & $73(19.2)$ & 78 (19.7) & $212(13.8)$ \\
\hline Hormone only & $52(6.8)$ & $96(25.3)$ & $194(48.9)$ & $342(22.2)$ \\
\hline None & $641(83.8)$ & $198(52.1$ & $99(24.9)$ & $938(60.8)$ \\
\hline Missing & 10 & 8 & 0 & 18 \\
\hline \multicolumn{5}{|l|}{ Therapy strategy, n (\%) } \\
\hline BCT (+- RT, no system. T.) & $80(10.5)$ & $121(31.8)$ & $69(17.4)$ & $270(17.5)$ \\
\hline BCT (+- RT, + system. T.) & $5(0.7)$ & $78(20.5)$ & $173(43.6)$ & $256(16.6)$ \\
\hline Mastect. (no RT, no system. T.) & $279(36.5)$ & $62(16.3)$ & $24(6.1)$ & $365(23.7)$ \\
\hline Mastect. (+- RT, + system. T.) & $119(15.6)$ & $104(27.4)$ & $125(31.5)$ & $348(22.6)$ \\
\hline Missing & 10 & 8 & 0 & 18 \\
\hline
\end{tabular}

$\mathrm{BCT}=$ Breast conserving therapy, $\mathrm{RT}=$ radiotherapy, mastect. $=$ mastectomy, adjuv. $=$ adjuvant, chemo $=$ chemotherapy, system. $=$ systemic, $\mathrm{T}=$ therapy.

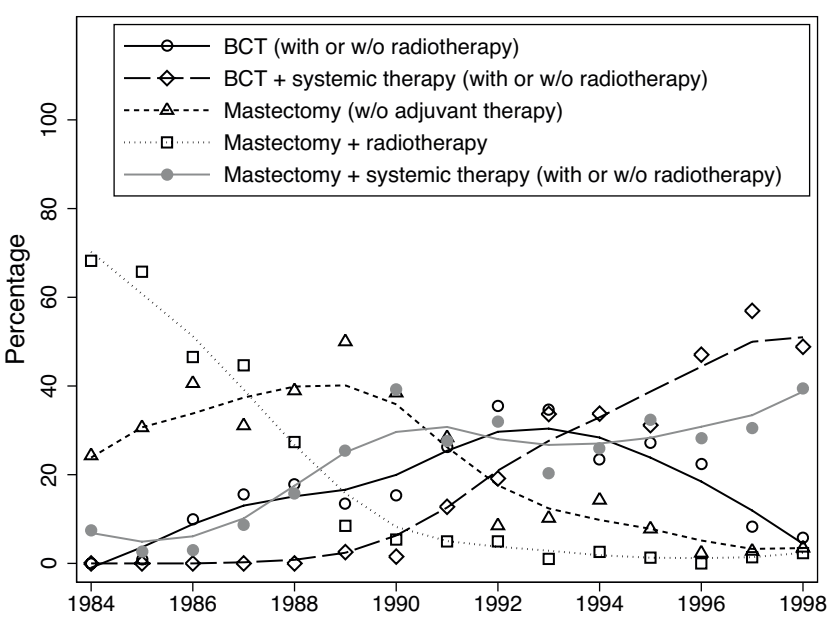

Fig. 3. Distribution of 5 treatment strategies. Percentage per year and smoothed over several years.

$60 \%$ of patients were lymph node negative. The number of nodes assessed increased dramatically over the study period. Whereas the percentage of patients in whom less than 10 nodes were assessed was close to $50 \%$ in the first period, in the third period this was an exception and the percentage dropped to $2.5 \%$. During the third period, more than 20 nodes were assessed in several patients with a node-negative tumor.

\section{Treatment}

Details about treatment strategies are given in table 2 and figures 3 and 4. In agreement with general changes worldwide, mastectomy (with or without $( \pm$ ) RT) was increasingly replaced by BCT plus RT. The Charité was the center most concerned in a randomized trial assessing the value of RT and
Tamoxifen in patients with a very good prognosis and BCT as surgery (GBSG 5 study). This explains the large number of patients treated by BCT without RT. Adjuvant therapy also changed radically. During the first period, most of the patients $(84 \%)$ did not receive either chemotherapy or hormonal treatment. In the third period, the corresponding percentage had dropped to $25 \%$; some of these patients were treated within the GBSG 5 study.

During the first period, most of the patients (73.4\%) had a mastectomy \pm RT, and did not receive adjuvant treatment. In the third period $61 \%$ had a BCT \pm RT and a systemic treatment. Figure 3 illustrates that this change was a continuous process over the years. Of interest is the curve for BCT \pm RT and no systemic treatment. At the beginning of the study period, BCT was unpopular and hardly anybody was treated with this procedure. However, in the early 90 s, about $20 \%$ of patients were treated this way. In the following years, systemic treatment became more popular, and since 1996 BCT ( \pm RT) + systemic therapy has become the leading strategy.

\section{Influence of Prognostic Factors on Choice of Treatment}

We investigated whether the treatment strategies applied depended on menopausal status, tumor size $(\leq 20 \mathrm{~mm}$ vs. $>20 \mathrm{~mm}$ ) and lymph node status. Figure 4 shows the relationship of 5 treatment strategies to 3 standard prognostic factors (in cancer often termed predictive factors). While menopausal status has only a weak influence, the effects of tumor size and lymph node status are clearly visible. Whereas BCT $( \pm \mathrm{RT})+$ systemic treatment was the preferred option for small tumors (during the third period), mastectomy $( \pm \mathrm{RT})+$ systemic therapy was the preferred choice for large tumors from the beginning of the 90s. A similar trend can also be seen for nodal status. This may in part be a result of the correlation between tumor size and nodal status. 
Fig. 4. Distribution of treatment strategies. Percentages per years in subgroups.

A1 Treatment strategies (menopausal status premenopausal) smoothed over several years. A2 Treatment strategies (menopausal status postmenopausal) smoothed over several years. B1 Treatment strategies (tumor size $\leq 20 \mathrm{~mm}$ ) smoothed over several years.

B2 Treatment strategies (tumor size $>20 \mathrm{~mm}$ ) smoothed over several years. C1 Treatment strategies (pN0) smoothed over several years. C2 Treatment strategies (positive lymph nodes) smoothed over several years.
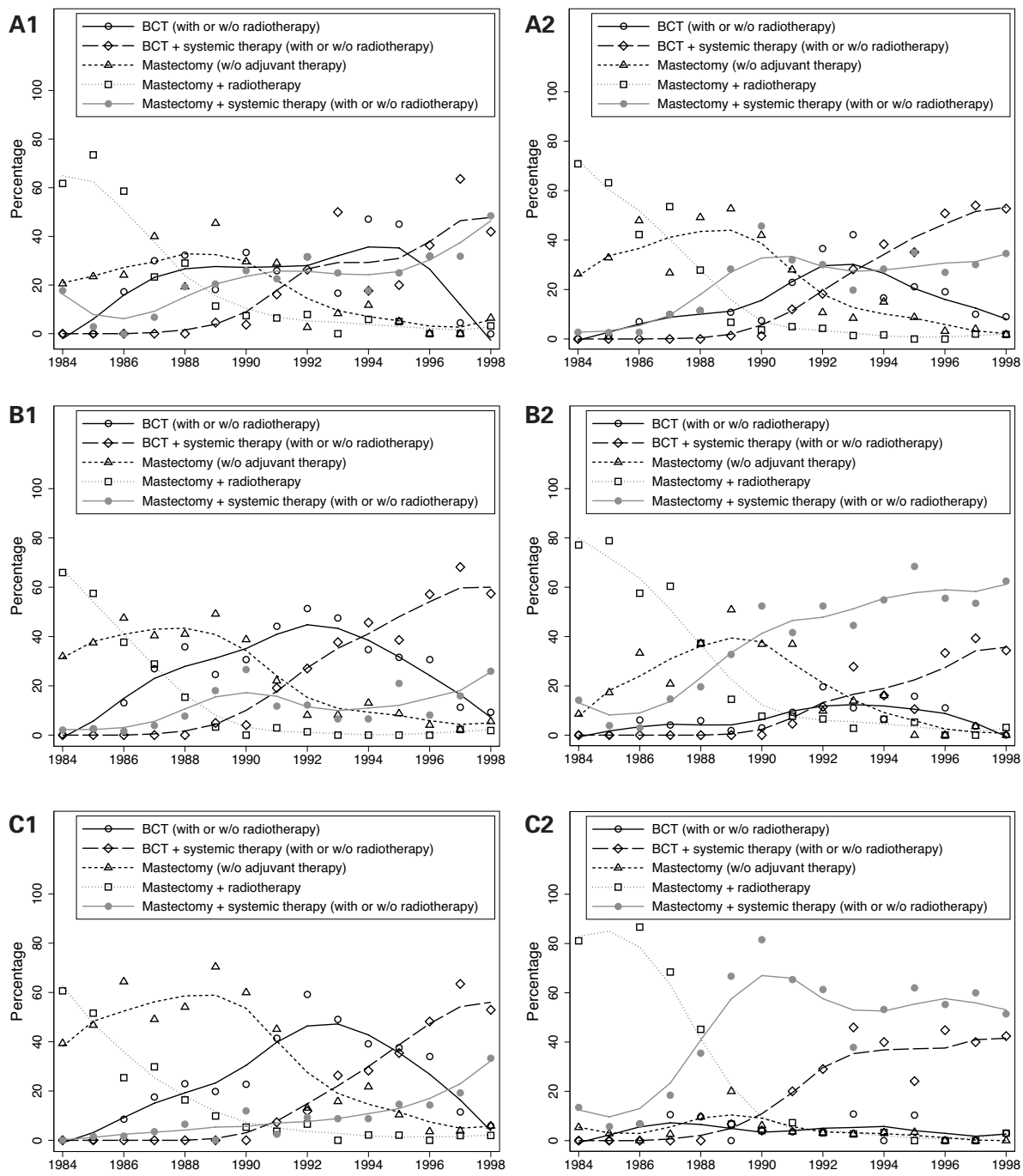

\section{Estimates of Survival Time in Several Subgroups}

\section{Time Periods}

Figure 5 shows our estimates of the overall survival rates over the 3 periods. Estimates for the first period are much lower than those for the second, while the rates for patients treated since 1994 show a further improvement. However, because of the differences in patient populations and treatments given, it is difficult to interpret these data. A complex multivariable model would be required to try and explain the effects originating from the time period, the prognostic factors and the different treatments.

\section{Standard Prognostic Factors}

In figure 6 we show the Kaplan-Meier estimates for overall survival in the subgroups age, tumor size and number of positive lymph nodes. Estimates for 5- and 10-year survival are given in table 3 . In agreement with current knowledge, the small group of young patients ( $\leq 40$ years) had the worst sur-

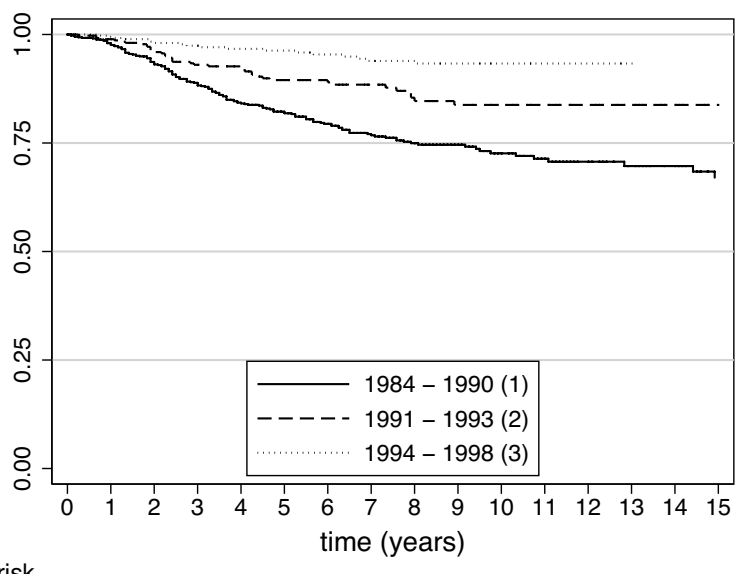

Number at risk

$\begin{array}{llllllll}\text { (1) } 775 & 657 & 508 & 365 & 226 & 130 & 82 & 60 \\ \text { (2) } 388 & 311 & 240 & 172 & 108 & 86 & 66 & 41 \\ \text { (3) } 397 & 335 & 252 & 204 & 159 & 93 & 17 & 0\end{array}$

Fig. 5. Kaplan-Meier estimates of overall survival by time period. 
A

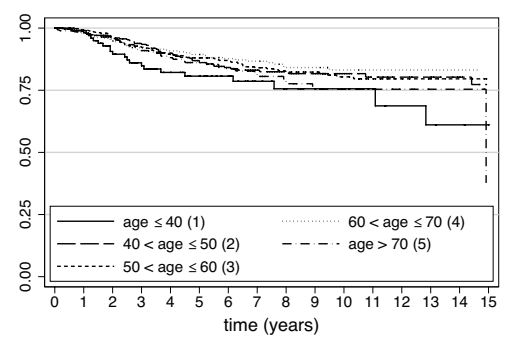

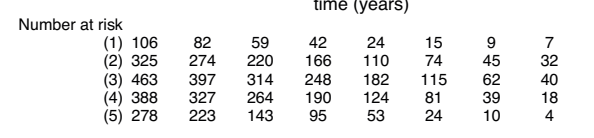

B

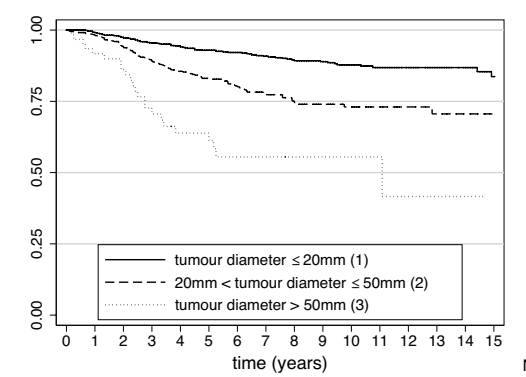

C

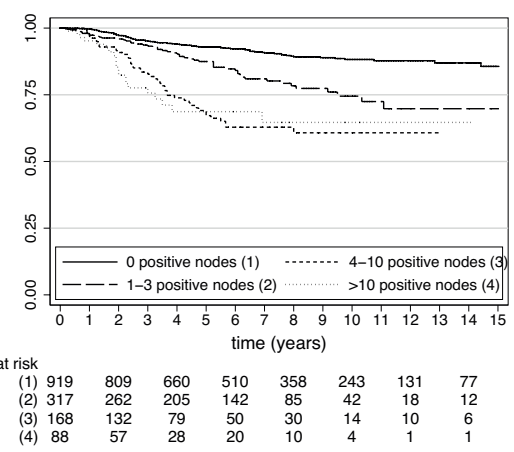

Fig. 6. Kaplan-Meier estimates of overall survival in subgroups of: A age, $\mathbf{B}$ tumor size, and $\mathbf{C}$ number of positive lymph nodes.

Table 3. Distribution of prognostic factors (percentage per factor) and Kaplan-Meier estimates of overall survival ( $95 \%$ confidence intervals, CI) at 5 and 10 years for various subgroups defined by standard prognostic factors for 1,560 patients. Except for age, all variables have some missing data. For details see table 1. Percentage are relative to all non-missing values

\begin{tabular}{|c|c|c|c|}
\hline Factor & Patients, n (\%) & $\begin{array}{l}5 \text {-year survival rate, \% } \\
\text { (CI) }\end{array}$ & $\begin{array}{l}\text { 10-year survival rate, \% } \\
(\mathrm{CI})\end{array}$ \\
\hline \multicolumn{4}{|l|}{ Age, years } \\
\hline$\leq 40$ & $106(6.8)$ & $80.7(70.6,87.6)$ & $75.6(63.2,84.3)$ \\
\hline $41-50$ & $325(20.8)$ & $86.1(81.2,89.7)$ & $81.7(76.1,86.1)$ \\
\hline $51-60$ & $463(29.7)$ & $88.0(84.3,90.9)$ & $80.4(75.3,84.5)$ \\
\hline $61-70$ & 388 (24.9) & $89.4(85.6,92.3)$ & $83.2(77.7,87.4)$ \\
\hline$>70$ & 278 (17.8) & $86.1(80.5,90.2)$ & $75.4(66.0,82.6)$ \\
\hline \multicolumn{4}{|l|}{ Meno. status } \\
\hline Premeno & $438(29.1)$ & $86.0(81.9,89.3)$ & $81.7(76.8,85.6)$ \\
\hline Postmeno & 1068 (70.9) & $87.5(85.1,89.5)$ & $79.7(76.3,82.7)$ \\
\hline \multicolumn{4}{|l|}{ Tumor size } \\
\hline$\leq 20 \mathrm{~mm}$ & $810(55.3)$ & $92.9(90.7,94.6)$ & $87.8(84.6,90.4)$ \\
\hline $21-50 \mathrm{~mm}$ & $592(40.4)$ & $82.8(78.9,86.0)$ & $73.0(67.5,77.8)$ \\
\hline$>50 \mathrm{~mm}$ & $64(4.4)$ & $61.2(46.1,73.2)$ & $55.5(39.9,68.5)$ \\
\hline $15-25 \mathrm{~mm}$ & $662(45.2)$ & $88.6(85.6,91.0)$ & $82.9(78.8,86.2)$ \\
\hline \multicolumn{4}{|l|}{ Positive nodes } \\
\hline 0 & 919 (61.6) & $92.9(90.9,94.5)$ & $88.2(85.3,90.6)$ \\
\hline $1-3$ & 317 (21.3) & $87.5(82.7,91.0)$ & $74.5(66.5,80.8)$ \\
\hline $4-10$ & 168 (11.3) & $67.2(58.0,74.8)$ & $60.8(50.6,69.4)$ \\
\hline$>10$ & $88(5.9)$ & $68.7(55.0,79.0)$ & $64.6(46.3,76.4)$ \\
\hline \multicolumn{4}{|l|}{ Grade } \\
\hline G1 & $291(21.7)$ & $94.4(90.6,96.6)$ & $88.7(83.4,92.4)$ \\
\hline G2 & $610(45.4)$ & $90.1(87.1,92.5)$ & $81.9(77.2,85.7)$ \\
\hline G3 & $442(32.9)$ & $79.3(74.6,83.2)$ & $73.7(67.5,78.9)$ \\
\hline
\end{tabular}

vival rate (fig. $5 \mathrm{~A}$ ). After 5 years the rate was $80.7 \%$, whereas all other age groups had similar survival rates, varying slightly between 86.1 and $89.4 \%$. The effect of tumor size was substantial with the estimate for 5-year survival ranging from 92.9 ( $\leq 20 \mathrm{~mm})$ over $82.8(21-50 \mathrm{~mm})$ to $61.2 \%$ (> $50 \mathrm{~mm})$ (fig. 5B). The number of positive nodes (fig. 5C) also indicated a strong effect. Whereas node-negative patients had 5-year survival rates of $92.9 \%$, the rate for patients with 4 or more positive nodes was around $68 \%$. The Kaplan-Meier estimates indicate that there was hardly any difference between the groups with 4-10 or $>10$ positive nodes. This can partly be explained by a potential underestimation of the number of positive nodes during the first time period (see table 1), in which several patients with more than 10 positive nodes were probably classified in the group 4-10. Grade also had a strong prognostic effect. Survival rates at 5 years ranged from $94.4 \%$ (G1) to $79.3 \%$ (G3).

\section{Discussion}

To assess effects of the particular periods of time, treatment strategies and prognostic factors, complex multivariable modeling is needed. This is beyond the scope of the current paper, but will be the subject of a follow-up paper. For more than 40 years, there have been recommendations worldwide that treatment should depend on some standard prognostic factors. A strong dependency of treatment strategies on several factors was illustrated for our population, leading to confounding of effects of treatment and prognostic factors. This may lead to dangerously misleading conclusions from univariate analyses of therapeutic strategies and we decided not to present them $[19,20]$.

The data presented here are from the analysis of 15 years of cancer surgery in a university clinic surgical ward. The advantage of such databases is the representative selection of patients in comparison to the evaluation in randomized studies. Primary breast carcinomas, although relevant for the certification of a German breast center (German Cancer Society and German Society for Senology), for which there was al- 
ready a previous contralateral carcinoma in the file were not included in the analysis (see: Exclusion Criteria), if these cases were included the figure for the original data set (fig. 1) would increase to more than 200 .

The data for the patient population are relatively complete with respect to their TNM classification considering that in 1999 (1 year after the end of recording the patients presented here), there were no tumor sizes available (TX or T missing) for $32.6 \%$ of reports sent to the cancer registry in Berlin [21].

Data collected between October 2003 and December 2008 at the Charité Breast Center, by a combination of breast cancer specialists from the 3 gynecological clinics and from the surgical clinic [22], showed a percentage of $12.7 \%$ pTis tumors. The majority of patients, however, had pT1 tumors $(53.6 \%$ after exclusion of patients with pTis tumors). In these data bilateral carcinoma were considered separately. For comparison, the present data (for 1984-1998) contained 6.5\% pTis tumors (relative to the original sample of 2,062 patients) and $48.6 \%$ pT1 tumors (52.0\% after exclusion of pTis tumors).

The analysis of patients from Berlin and Munich shows a percentage of pT1 tumors of $48.4 \%$ from $1980-1985$ and a percentage of $60.7 \%$ from $1986-1990$. This number is surprisingly small considering the long period of time and the relatively large size of the clinics [3]. The clinics performing surgeries have little influence on the diagnostics, which depend on an already existing screening program, which results in the discovery of a high number of early stage pT1 tumors (stage 1).

Although there have been more preparations of lymph nodes over the course of time, this appears to have little influence on the number of affected lymph nodes (table 1). Obviously, there has always been a tendency of directing conspicuous lymph nodes from surgery preparations to histological examinations.

Changes in grading have occurred over the course of the study period, possibly because diagnostics have become more exact. The criteria for the grade of polymorphism (estimated) remained practically unchanged for the 3 parameters that were adopted in the grading. After the modification of the previous grading [23] by Elston and Ellis [24], mitoses had not only been estimated but also counted, and the bright field standardized [25]. In addition, because of the participation in multicenter studies, higher quality requirements were applied, and the histological results from relevant patients were checked by an external pathological unit. The same applied for the percentage of tubular differentiation. Obviously, these quality criteria gradually gained acceptance in periods 2 and 3 .

Table 1 shows that the number of positive lymph nodes did not increase proportionally to the number of nodes taken. It is possible that this is because the preparation of lymph nodes was done less carefully. This raises the issue of whether it is necessary to take at least 10 lymph nodes, as required by pathologists in Germany.

Since 1991, 51 patients undergoing BCT did not receive RT as they were participating in the GBSG-5 study [26], and this accounts for the number of patients with BCT and not receiving RT in the last 2 cohorts, which exceeds the usually expected number of patients refusing RT [14] or the number of patients who did not receive RT due to contraindications.

The percentage of patients over an age of 70 obviously decreases over the course of the 3 periods because of the way the transferal was conducted. Age (fig. 6A) has an impact on breast cancer specific survival. However, death may have been due to causes other than cancer, which leads to a blurry outcome at the beginning of the study period. In our study, the overall survival is taken into account, which shows a higher death rate with higher age compared to survival specific for breast cancer.

It is difficult to compare survival probabilities on an international level, apart from different references such as relative, breast cancer-specific or overall survival, because there is also an ethnic component to be considered [27]. According to van de Water et al. [28], death specifically caused by breast cancer in postmenopausal women receiving hormones after an average follow-up of 5.1 years amounts to $78 \%$ for women of $<65$ years of age, to $56 \%$ for women between 65 and 75 years, and to $36 \%$ for women $>75$ years.

The survival probability for breast cancer patients steadily increased over the period 1970-2000 in North, Central and South Europe [29], whereas in Russia and in Ukraine, there was an increase from 1960 to 2002 [30]. Because of fundamental difference in time periods, patient populations and treatment strategies, it does not make sense to compare results from the Charité to results from other clinics in German speaking countries [3-5].

An east-west comparison in Germany is also difficult because of the tendency to rely on the Saarland state registry [31]. In this epidemiological registry, the number of pT1 tumors was specified as $32.6 \%$ for $1988-1991$, 36.2\% for $1992-$ 1995 and $38 \%$ for $1996-1999$. The 5-year survival rates were $73.2 \%$ from 1992/93 to 1996, and at 77.1\% from 1996 to 1997. In the GDR, however, there was a central registry making it very difficult for the citizens not to be accounted for. The study group of Brenner attempted to make such a comparison, and for the 5-year relative survival rate for the GDR in the years 1984-1986 gave a value of $52 \%$, while in the period from 1979-1983, the percentage was at $68 \%$ in Western Germany. Since then, the rates have become practically aligned [32]. The clinic registry presented here shows the absolute survival rate.

\section{Acknowledgement}

We would like to thank Clemens Wachter for his support during the preparation of this paper.

\section{Disclosure Statement}

The authors declare no conflict of interest. 


\section{References}

1 Early Breast Cancer Trialists' Collaborative Group. Effects of adjuvant tamoxifen and of cytotoxic therapy on mortality in early breast cancer: an overview of 61 randomized trials among 28,896 women. N Engl J Med 1988;319:1681-1692.

$\checkmark 2$ Early Breast Cancer Trialists' Collaborative Group. Effects of radiotherapy and surgery in early breast cancer. An overview of the randomized trials. N Engl J Med 1995;333:1444-1455.

3 Janni W, Sommer H, Strobl B, Rack B, Klanner E, Hantschmann P, Rammel G, Harms G, Dimpfl T: Fortschritte in der Früherkennung des Mammakarzinoms in den Jahren 1981-1990. Ergebnisse einer Longitudinalstudie. Dtsch Med Wochenschr 2003;128:601-606.

4 Du Bois A, Vogel P, Beutel B, Traut A, FisselerEckhoff A, Hils R, Lück H-J: Prognosefaktoren für das Rezidiv beim Mammakarzinom am Kollektiv der HSK Wiesbaden 1998-2003. Senologie 2009;6:33-41.

5 Van Ewijk RJG, Schwentner L, Wöckel A, König J, Kreienberg R, Blettner M: Trends in patient characteristics, treatment and survival in breast cancer in a non-selected retrospective clinical cohort study of 2,600 patients. Arch Gynecol Obstet 2013;287:103-110.

6 Winzer K-J, Guski H, Frohberg H-D: Diagnostik und Therapie des Mammakarzinoms - eine interdisziplinäre Aufgabe. Med Aktuell 1991;17:16-19.

7 EORTC Breast Cancer Cooperative Group. Standards for the assessment of estrogen receptors in human breast cancer. Eur J Cancer 1973;9:379384.

8 Winzer K-J, Saul G, Sinn B, Kranz D, Wolff H, Rose H: Untersuchungen zum Östrogenrezeptorstatus von Mammakarzinompatientinnen. Zentralbl Chir 1986;111:915-920.

$\checkmark 9$ Jonat W, Maass H, Stegner HE: Immunohistochemical measurement of estrogen receptors in breast cancer tissue samples. Cancer Res 1986; 46:4296s-4298s.

10 Winzer K-J, Dallüge K-H, Frohberg H-D, Guski H: Kritische Diskussion und eigenes Vorgehen zur Technik der Lumpektomie mit axillärer Lymphonodektomie und Nachbestrahlung beim kleinen Mammakarzinom. Zentralbl Chir 1989;114:20-31.

-11 Fisher B, Wolmark N, Fisher ER, Deutsch M: Lumpectomy and axillary dissection for breast cancer: Surgical, pathological, and radiation considerations. World J Surg 1985;9:692-698.
Veronesi U, Zucali R, Del Vecchio M: Conservative treatment of breast cancer with QU.A.R.T. technique. World J Surg 1985;9:676-681.

13 Winzer K-J: 1990 Versuch der Gründung einer Gesellschaft für Senologie und Integration der Kollegen aus der DDR in die Deutsche Gesellschaft für Senologie - ein persönlicher analysierender Rückblick nach 20 Jahren. Dtsch Gesellschaft Chir Mitt 2012;41:175-180.

14 Shafie S, Brooks SC: Characteristics of the dextran-coated charcoal assay for estradiol receptor in breast cancer preparations. J Lab Clin Med 1979; 94:784-798.

15 Remmele W, Stegner WH: Vorschlag zur einheitlichen Definition eines Immunreaktiven Score (IRS) für den immunhistologischen Östrogenrezeptor-Nachweis (ER-ICA) im Mammakarzinomgewebe. Pathologe 1987;8:138-140.

16 Winzer K-J, Kranz D, Enzmann G: Zytochemische Östrogenrezeptorbestimmung bei Mammatumoren. Zentralbl Chir 1987;112:1155-1159.

17 Winzer K-J, Bellach J:Wertigkeit der routinemäßig erfassten Nachsorgedaten bei Brustkrebspatientinnen. Zentbl Chir 2010;153:257-261.

18 Kaplan EL, Meier P: Nonparametric estimation from incomplete observations. J Am Stat Assoc 1958;53:457-481.

19 Sauerbrei W, Schumacher M: Aspekte der statistischen Evaluation neuer Prognosefaktoren: Illustration bei Studien in der Onkologie. Geburtshilfe Frauenheilkd 1999;59: 483-487.

20 Schumacher M, Holländer N, Schwarzer G, Binder H, Sauerbrei W: Prognostic factor studies; in Crowley J, Hoering A (eds): Handbook of Statistics in Clinical Oncology, 3rd ed. Chapman and Hall/CRC 2012, pp 415-470.

21 Giersiepen K, Haartje U, Hentschel S, Katalinic A, Kieschke J: Brustkrebsregistrierung in Deutschland: Tumorstadienverteilung in der Zielgruppe für das Mammographie-Screening. Dtsch Ärztebl 2004;101.30:A-2117/B-1769/C-170.

22 Winzer K-J, Gruber C, Badakhshi H, Hinkelbein M, Denkert C: Compliance der Patientinnen in Bezug zur empfohlenen Strahlentherapie beim Mammakarzinom. Strahlenther Onkol 2012;188: 788-794.

23 Bloom HJ, Richardson WW: Histological grading and prognosis in breast cancer; a study of 1409 cases of which 359 have been followed for 15 years. Br J Cancer 1957;11:359-377.
4 Elston CW, Ellis IO: Pathological prognostic factors in breast cancer. I. The value of histological grade in breast cancer: experience from a large study with long-term follow-up. Histopathology 1991;19:403-410.

25 Bässler R, Böcker W, Hermanek P, et al.: Die gegenwärtige Situation des Gradings beim Mammakarzinom. Pathologe 1992;13:130-134.

26 Winzer KJ, Sauerbrei W, Braun M, Liersch T, Dunst J, Guski H, Schumacher M: German Breast Cancer Study Group (GBSG): Radiation therapy and tamoxifen after breast-conserving surgery: Updated results of a $2 \times 2$ randomised clinical trial in patients with low risk of recurrence. Eur J Cancer 2010;46:95-101.

27 Warner ET, Tamimi RM, Hughes ME, Ottesen RA, Wong YN, Edge SB, Theriault RL, Blayney DW, Niland JC, Winer EP, Weeks JC, Partridge AH: Time to diagnosis and breast cancer stage by race/ ethnicity. Breast Cancer Res Treat 2012;136:813821.

28 Van de Water W, Markopoulos C, van de Velde CJ, Seynaeve C, Hasenburg A, Rea D, Putter H, Nortier JW, de Craen AJ, Hille ET, Bastiaannet E, Hadji P, Westendorp RG, Liefers GJ, Jones SE: Association between age at diagnosis and diseasespecific mortality among postmenopausal women with hormone receptor-positive breast cancer. JAMA 2012;307:590-597.

29 Levi F, Bosetti C, Lucchini F, Negri E, La Vecchia C: Monitoring the decrease in breast cancer mortality in Europe. Eur J Cancer Prev 2005;14:497-502.

30 Hirte L, Nolte E, Bain C, McKee M: Breast cancer mortality in Russia and Ukraine 1963-2002: An age-period-cohort analysis. Int J Epidemiol 2007; 36:900-906.

31 Holleczek B, Arndt V, Stegmaier C, Brenner H: Trends in breast cancer survival in Germany from 1976 to 2008 - a period analysis by age and stage. Cancer Epidemiol 2011;35:399-406.

32 Jansen L, Gondos A, Eberle A, Emrich K, Holleczek B, Katalinic K, Brenner H, GEKID Cancer Survival Working Group: Cancer survival in Eastern and Western Germany after the fall of the iron curtain. Eur J Epidemiol 2012;27:689693. 